\title{
DIVERSIDADE DE GUILDAS TRÓFICAS EM SCARABAEINAE (COLEOPTERA, SCARABAEIDAE) DE MATA ATLÂNTICA
}

\author{
Lorena Pereira Cerqueira ${ }^{1}$ e Priscila Paixão Lopes ${ }^{2}$ \\ 1. Bolsista PIBIC/Fapesb, Graduando em Licenciatura em Ciências Biológicas, Universidade Estadual de Feira de Santana, \\ e-mail: lolycerqueira@gmail.com \\ 2. Orientador, Departamento de Ciências Biológicas, Universidade Estadual de Feira de Santana, e-mail: pplc29@ gmail.com
}

PALAVRAS-CHAVE: serviços ecológicos; rola-bosta; complementaridade de nicho

\section{INTRODUÇÃO}

Os Scarabaeinae (Coleoptera, Scarabaeidae) também conhecidos como besouros rolabosta, são insetos detritívoros que se alimentam de fezes, carcaças, frutos em decomposição e fungos em decomposição ${ }^{1}$. Por serem organismos detritívoros eles possuem fundamental importância na manutenção dos ecossistemas ao qual estão inseridos e isso se explica pela remoção e reingresso da matéria orgânica no solo ${ }^{2}$. Por causa desse comportamento, os Scarabaeinae realizam diversos serviços ecológicos, como o controle biológico natural de organismos detritívoros ${ }^{3}$. Por terem alta sensibilidade a mudanças ambientais ${ }^{4}$ podem ser utilizados como organismos bioindicadores, principalmente em florestas e savanas tropicais ${ }^{5}$, respondendo a mudanças através da estrutura de sua comunidade, populações, riqueza e abundância nos diferentes ecossistemas ${ }^{6}$.

A atratividade dos Scarabaeinae por diferentes recurso faz com que eles possam ser divididos em guildas tróficas ${ }^{7}$. Algumas espécies são especialistas em um tipo de recurso, outras demonstram apenas preferência e outras são generalistas ${ }^{1}$. Desta forma há complementaridade de nicho entre espécies de rola-bosta, pois utilizando recursos parecidos (ex, diversos tipos de fezes) podem desempenhar o mesmo papel na manutenção dos ecossistemas, mas abrangendo recursos de variadas origens. Desta forma, estabelecemos como princípio teórico que áreas com maior quantidade e diversidade de fontes de recursos suportam comunidades mais ricas e com maior amplitude de espécies especialistas em recursos específicos que áreas empobrecidas do ponto de vista estrutural.

Diante disto testaremos as seguintes hipóteses: 1) haverá maior dissimilaridade de composição de espécies em recursos de natureza distinta (fezes, carcaças ou frutos em decomposição) do que entre recursos de mesma natureza; 2) fezes de onívoros atrairão uma riqueza maior de espécies do que fezes de herbívoros; 3) fragmentos de mata com mesma cobertura vegetal apresentarão comunidades de rola-bosta com estrutura mais similar; 4) em áreas menores e com interferência humana haverá uma riqueza menor de espécies e menor diversidade de guildas tróficas do que em áreas mais conservadas.

\section{MATERIAL E MÉTODOS}

O estudo foi realizado na APA do Pratigi, que engloba os municípios de Ituberá, Nilo Peçanha, Igrapiúna, Piraí do Norte e Ibirapitanga. Com 171 mil hectares, está inserida na porção setentrional do Corredor Central da Mata Atlântica e possui grandes remanescentes florestais com elevado valor de conservação, mas sob forte ameaça de degradação ${ }^{8}$. Estima-se que na área da APA existam remanescentes de Mata Atlântica que abrangem 21,5\% de sua área total. Foram amostrados seis fragmentos em estado médio ou avançado de recuperação (áreas: 344, 342, 190, 1150, 17 e 15,9 ha). Em cada um dos fragmentos florestais foi montada uma grade de nove pontos amostrais (mínimo 50m um do outro, e da borda do fragmento) para coleta dos besouros. Cada ponto amostral foi composto por seis armadilhas de queda, cada qual com um tipo de isca: carcaças (porco, baço de boi, e sardinha), fezes (humanas e bovinas) e banana em decomposição. As armadilhas permaneceram no campo por 48horas, e 
depois os insetos foram recolhidos, fixados em álcool 70\%, e levados ao laboratório para triagem, montagem e identificação. A abertura do dossel foi medida através de fotografias digitais com lente olho de peixe (hemisférica), e analisadas com o programa GLA (1999) ${ }^{9}$.

As espécies com mais de 10 indivíduos foram classificadas em guildas segundo sua frequência em cada isca, sendo consideradas especialistas as espécies que ocorreram com frequência superior a $80 \%$ no mesmo recurso. Espécies com ocorrências diferentes destes valores foram consideradas generalistas.

Foram comparadas a riqueza e abundância entre as guildas tróficas (coprófagos, necrófagos e generalistas) e dentro das guildas amostradas com mais de uma isca (coprófagos e necrófagos), e estas relacionadas às variações de abertura do dossel e área dos fragmentos (ANOVA fatorial). A distribuição de guildas entre fragmentos foi igualmente analisada.

As composições das comunidades de cada fragmento foram comparadas por uma NMDS, utilizando matrizes de similaridade construídas com as métricas de Jaccard e de BrayCurtis, tanto usando comparação de espécies quanto das várias guildas. No caso de NMDS gerados pela métrica de Bray-Curtis, os grupos foram avaliados através de ANOSIM, para validação de significância.

\section{RESULTADOS E DISCUSSÃO}

Foram encontrados 2.181 espécimes de Scarabaeinae, distribuídos em 34 espécies nas seis áreas amostradas. A espécie mais abundante foi Canthonella silphoides (Harold, 1867) com 1074 indivíduos (49,24\%). A segunda mais abundante foi Dichotomius (L.) gr. sericeus sp.nov. com 553 indivíduos $(25,35 \%)$. Em relação à abundância de indivíduos por isca, a mais atrativa foi a de fezes humanas, com 1398 indivíduos. As iscas de carcaça (baço, peixe e porco) atraíram quantidades bem similares de indivíduos (porco: 266, peixe: 260 e baço: 209 indivíduos). Sete espécies apresentaram preferência (ocorrência $>80 \%$ dos indivíduos por recurso) por fezes e três espécies apresentaram preferência por iscas de carcaça. Por apresentar abundância não tão acentuada por um ou outro recurso, as demais espécies foram consideradas generalistas, com abundância um pouco maior em fezes humanas (Tabela 1).

Tabela 1. Classificação das espécies amostradas em fragmentos florestais secundários da APA do Pratigi* quanto à preferência alimentar.

\begin{tabular}{lccccl}
\hline Espécie & Fezes & Carne & Fruta & Total & Classificação** \\
\hline Ontherus $($ O.) ulcopygus & $100 \%$ & $0 \%$ & $0 \%$ & 17 & Coprófaga \\
Onthophagus haematopus & $94 \%$ & $6 \%$ & $0 \%$ & 66 & Coprófaga \\
Sylvicanthon obscurus & $90 \%$ & $10 \%$ & $0 \%$ & 30 & Coprófaga \\
Eurysternus caribaeus & $89 \%$ & $11 \%$ & $0 \%$ & 38 & Coprófaga \\
Dichotomius $($ D.) mormon & $88 \%$ & $13 \%$ & $0 \%$ & 48 & Coprófaga \\
Canthidium $($ E.) sp3 & $81 \%$ & $19 \%$ & $0 \%$ & 80 & Coprófaga \\
Canthon $($ Pel.) prasinus & $81 \%$ & $17 \%$ & $2 \%$ & 58 & Coprófaga \\
Canthidium $($ E.) sp2 & $76 \%$ & $24 \%$ & $0 \%$ & 17 & Generalista \\
Canthonella silphoides & $70 \%$ & $30 \%$ & $0 \%$ & 1074 & Generalista \\
Eurysternus cyanescens & $68 \%$ & $32 \%$ & $0 \%$ & 25 & Generalista \\
Deltochilum (E.) brasiliensis & $62 \%$ & $38 \%$ & $0 \%$ & 13 & Generalista \\
Eurysternus nanus & $61 \%$ & $39 \%$ & $0 \%$ & 38 & Generalista \\
Dichotomius (L.) gr. sericeus sp.nov. & $53 \%$ & $45 \%$ & $2 \%$ & 553 & Generalista \\
Coprophanaeus (Meg.) bellicosus & $0 \%$ & $100 \%$ & $0 \%$ & 47 & Necrófaga \\
Deltochilum calcaratum & $0 \%$ & $100 \%$ & $0 \%$ & 14 & Necrófaga \\
Canthon nigripennis & $0 \%$ & $100 \%$ & $0 \%$ & 10 & Necrófaga \\
\hline
\end{tabular}

* Representação apenas das espécies com mais de 10 indivíduos coletados.

**Bases de Classificação: Espécies com ocorrência > 80\% dos indivíduos em um grupo de recurso. 
Dentre os coprófagos, todos tiveram acima de $80 \%$ de ocorrência em fezes humanas, enquanto que os necrófagos não demonstraram preferência acentuada por qualquer das iscas de carcaça disponibilizadas (máximo registrado de $60 \%$, em carcaça de porco).

$\mathrm{Na}$ comparação de riqueza e abundância entre guildas tróficas, relacionadas à cobertura vegetal e métricas dos fragmentos, tanto a área quanto a dieta e a interação das duas variáveis tiveram efeito significativo (Figura 1). A significância das diferenças foi dada na maioria dos casos pela maior ocorrência em fezes registradas nos fragmentos maiores (Adeilton, Waldemar e André). As análises de similaridade apontaram, no entanto, que não houve diferenciação da composição das guildas de coprófagos, necrófagos e generalistas.

A primeira hipótese foi corroborada para as iscas de carcaça mostrando a similaridade entre a composição neste tipo de iscas, porém o padrão não ocorre nas armadilhas iscadas com fezes, sendo que a composição entre fezes humanas e bovinas é diferente. Para os necrófagos, isso pode se explicar pela não especialização em apenas um tipo de carcaça, pela baixa disponibilidade de recurso no ambiente.

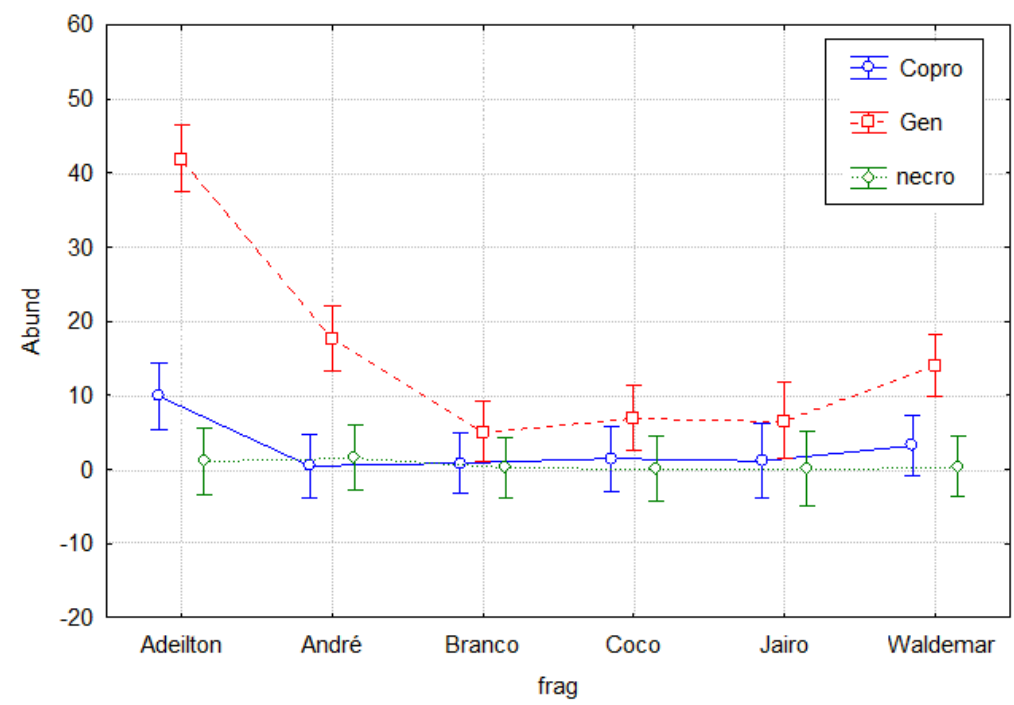

Figura 1. ANOVA Fatorial da interação das variáveis de área e dieta sobre as comunidades de Scarabaeinae da APA do Pratigi $(\mathrm{F}(10,321)=10,057 ; \mathrm{p}=0,0000)$. Barras verticais indicam Intervalo de Confiança de $95 \%$.

A segunda hipótese foi confirmada $(\mathrm{F}(24,162)=2,3983 ; \mathrm{p}=0,00068)$ (Figura 2). Isso pode ser explicado porque em ambientes neotropicais, em função da extinção dos grandes herbívoros, os Scarabaeinae especializaram-se em fezes de primatas, porque eram as fezes mais abundantes no ambiente ${ }^{10}$. Alternativamente, os onívoros possuem uma alimentação muito mais diversificada em relação aos herbívoros, e por isso é de se esperar que as fezes humanas possuam muito mais compostos voláteis e odor mais intenso (maior concentração de compostos voláteis), atraindo um número muito maior de espécies ${ }^{2}$.

A terceira hipótese não foi confirmada, pois o padrão de distribuição de espécies é bastante parecido nos seis fragmentos de mata, e estes não foram significativamente diferentes em relação ao nível de abertura do dossel.

A quarta hipótese foi confirmada em relação à riqueza e abundância $(p<0,001$; $\mathrm{R}=0,6772$ ), o que pode ser explicado pela resposta positiva de mamíferos, principais fontes de recursos para os besouros rola-bosta, a esses fatores dos fragmentos, mas não houve diferenciação na quantidade de guildas tróficas. No entanto, a relação com nível de perturbação não foi possível, pois todos os fragmentos não são diferentes em termos de abertura de dossel, o que não permite a relação dessa variável com o nível de perturbação. 


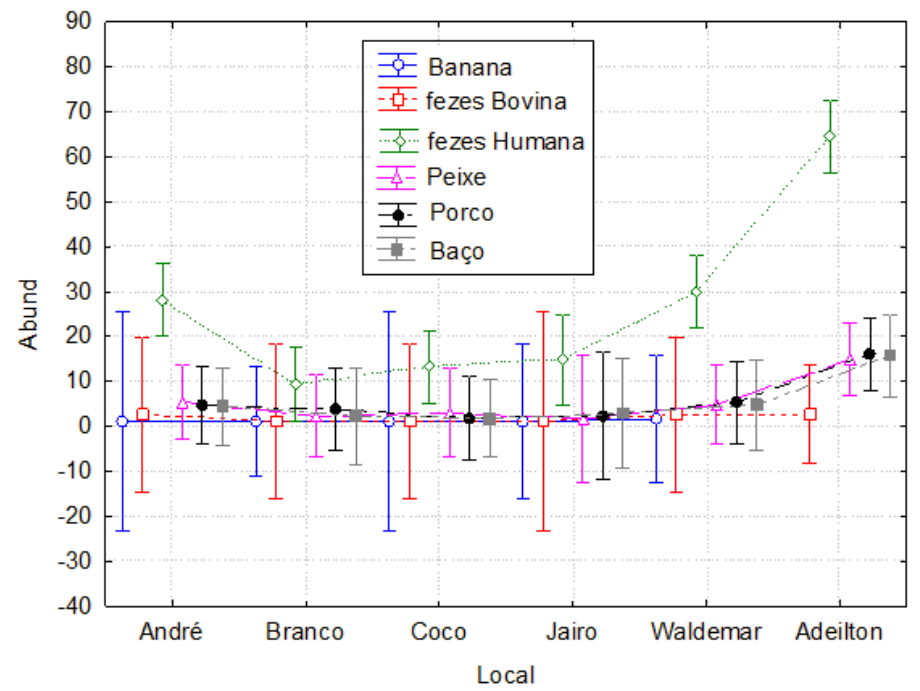

Figura 2. ANOVA Fatorial da interação das variáveis de área e tipo de isca sobre as comunidades de Scarabaeinae da APA do Pratigi $(\mathrm{F}(24,162)=2,3983 ; \mathrm{p}=0,00068)$. Barras verticais indicam Intervalo de Confiança de $95 \%$.

\section{CONSIDERAÇÕES FINAIS}

Conclui-se que neste ambiente o padrão semelhante ao encontrado em outros biomas se repete devido à adaptação a utilizar recursos odoriferamente mais atrativos.

\section{REFERÊNCIAS}

1. HALFFTER, G.; MATTHEWS, E. 1966. The natural history of dung beetles of the subfamily Scarabaeinae (Coleoptera, Scarabaeidae). Folia Entom. Mex. 12-14, 1-312.

2. HANSKI, I.; CAMBEFORT, Y. 1991. Dung Beetle Ecology. Princeton University Press.

3. FLECHTMANN, C. A.; RODRIGUES, S. R.; SENO, M. C. Z. 1995. Controle Biológico da mosca-dos-chifres (Haematobia irritans irritans) em Selvíria, Mato Grosso do Sul. 3. Levantamento de espécies fimícolas associadas à mosca. Rev. Bras. Entom., 39(2): 249-58.

4. HALFFTER, G.; FAVILA, M. H. 1993. The Scarabaeinae (Insecta: Coleoptera), an animal group for analysing, inventorying and monitoring biodiversity in tropical rainforest and modified landscapes. Biol. Intern., 27: 15-21.

5. KLEIN, B. C. 1989. Effects of Forest Fragmentation on Dung and Carrion Beetle Communities in Central Amazonia. Ecology 70, 1715-1725.

6. ANDRESEN, E. 2003. Effect of forest fragmentation on dung beetle communities and functional consequences for plant regeneration. Ecography, Copenhagen, 26: 87 - 97.

7. ROOT, R. 1967. The niche exploitation pattern of the blue-gray gnatcatcher. Ecol. Monogr. 37, 317-350.

8. http://www.oct.org.br/apa-do-pratigi/Apresentacao/19

9. FRAZER, G.W.; CANHAM, C.D.; LERTZMAN, K.P. 1999. Gap Light Analyzer (GLA), Version 2.0: Imaging software to extract canopy structure and gap light transmission indices from true-colour fisheye photographs. Simon Fraser University / Institute of Ecosystem Studies.

10. CAMBEFORT, Y. 1991. Biogeography and evolution. In: HANSKI, I.; CAMBEFORT, Y. (eds.). Dung Beetle Ecology. Princeton University Press. pp. 198-210. 